\title{
GIS-based approach for evaluating a community intrinsic resilience index
}

\author{
Firas Gerges $^{1,2} \cdot$ Hani Nassif $^{3} \cdot$ Xiaolong Geng $^{1} \cdot$ Holly A. Michael $^{4}$. \\ Michel C. Boufadel ${ }^{1}$ iD
}

Received: 21 January 2021 / Accepted: 25 October 2021 / Published online: 6 November 2021

(c) The Author(s) 2021

\begin{abstract}
Community resilience refers to the degree to which a community can survive and recover following a disaster. While resilience itself is well understood, decisions that would enhance resilience are interdependent and involve various stakeholders. There are indices for evaluating community resilience, but these have the shortcoming that they compare between political entities, such as counties. Therefore, one cannot ascertain that a county is truly resilient. In addition, natural disasters depend on the landscape and thus have no relation to the political boundaries. Our metric aims to capture the information into a Community Intrinsic Resilience Index (CIRI), which embodies the resilience level of four critical sectors: transportation, energy, health and socio-economic. As a case study, we computed CIRI for the counties within New Jersey. Results showed that within NJ, CIRI ranged from 63 to $80 \%$. A post-disaster CIRI, following a scenario of flooding, revealed that two coastal counties would have low CIRI values due to the reduction in the road area and/or the GDP (local economy shut down) to below minimum values. We believe that our platform would further advance the efforts to fill the gap between resilience research and applications and would help decision and policy makers to integrate resilience within the planning and design phases of disaster management.
\end{abstract}

Keywords Resilience $\cdot$ Vulnerability $\cdot$ Natural hazards $\cdot$ Climate change $\cdot$ Risk management · GIS

\section{Introduction}

Resilience is a general term that refers to the ability of a system to recover "quickly" from difficulties. The time frame depends on the system under consideration. Resilience can be applied to computer networks facing cyber-attacks (Gouglidis and Hutchison 2017) or to an ecosystem recovering from an oil spill and producing services (NRC 2013). We are interested herein in the resilience of a community with its various components to natural hazard. Community resilience has been defined extensively in various studies. Mileti

Michel C. Boufadel

boufadel@gmail.com

Extended author information available on the last page of the article 
(1999) and Bosher and Chmutina (2017) view it as the capacity of a community to respond using its available resources and recover from hazard situations. Pfefferbaum et al. (2008) define it as the ability to execute efficient actions to reduce the consequences of particular problems such as a flood. Norris et al. (2008) consider community resilience as a process that links certain adaptive capacities to constructive course of functioning and to adjustment after adverse events. Cutter et al. (2010) explain community resilience as the myriad of capacities embraced through interventions and policies that enhance the ability of a community to respond and recover from disasters.

Patel et al. (2017) identified a set of elements that constitute community resilience in their attempt to review resilience definitions. These elements include communication, health, preparedness, governance and leadership. In this paper, we regard resilience as the degree to which a community can prepare for, respond to, and recover following a disaster.

Although one is commonly interested in resilience in response to a particular event such as a hurricane, one would need to factor in the non-stationarity of the climate due to global climate change (Karl and Trenberth 2003; Karl et al. 2009). In particular, not only the stressors, such as hurricanes, change over time (their intensity increases), but also the response of communities (natural and constructed to it). However, it is conceivable that one could assume stationarity over smaller time scales, such as a decade or two decades. The non-stationarity could be sometimes accounted for through "safety factors" (Kilgore et al. 2019).

The impact of climate change on the environment has become increasingly visible today with the rise of sea level and the increased severity of hurricanes and heatwaves. Scientists are predicting a significant rise in temperature over the next century, and a sever increase in climate change effects over time (Parry et al. 2007; Stocker et al. 2013). According to the Fourth National Climate Assessment released by the US Global Change Research Program (USGCRP 2017), the USA will face long-term impacts of climate change, including higher temperatures, longer frost-free and growing seasons, increased rainfall rates and storm intensity, in addition to an expected 1-4 feet rise in sea level by 2100 . Facing these consequences and the associated increased number of natural disasters, a research attempt to better understand resilience is crucial.

When studying and assessing hazards and the preparedness of communities, agencies are focusing more on resilience instead of disaster vulnerability given that resilience is interpreted as more preemptive (Cutter et al. 2008). In other words, federal agencies are directing their efforts toward enhancing a community resilience instead of focusing on reducing its vulnerability. The focus on resilience rather than vulnerability is of a great importance, as it integrates better the engagement of the population. Subsequently, communities and officials are putting more emphasis on resilience related studies in order to adopt resilience principles through new policies (Cutter 2016; Bakkensen et al. 2017). Also, as the damage to communities does not occur only during the disaster, but also in subsequent weeks (or maybe years), resilient communities are considered less harmed following a disaster than non-resilient communities (Yoon et al. 2016).

When discussing community resilience, social vulnerability emerges as an important factor/outcome (Bergstrand et al. 2015). The rationale behind linking social vulnerability to a community resilience can be appreciated when observing how certain social segments (poor, elderly, uneducated people, etc.) are less likely to survive or recover after certain hazardous events (Cochrane 1975; Morrow 1999; Juntunen 2004; Blaikie et al. 2005).

Various frameworks have emerged to describe aspects of community vulnerability or resilience (Lavelle et al. 2015; Serfilippi and Ramnath 2018; Koliou et al. 2020), ranging from numerical indices (Cutter et al. 2010; Peacock et al. 2010; Flanagan et al. 2011; 
Foster 2012) to surveys and scorecards (Berke et al. 2015; Khazai et al. 2018). These approaches differ greatly in their purpose, tools and potential recommendations, which is due to the fact that the science of community resilience is still evolving. In our assessment, a shortcoming of these approaches is their ability to create particular actions.

The objective of this paper is to present an index to represent the resilience level of communities based on select easily measured attributes. The index would be based on different sectors that affect the community well-being especially in relation to single major events (i.e., a disaster). The selected sectors are transportation, energy, health and socio-economic state. The index, labeled, Community Intrinsic Resilience Index (CIRI), compares each attribute in the four sectors to an ideal value and then reports the value as percentage of that ideal value. This is different than existing approaches where the attributes in various communities (e.g., counties) are ranked, and a comparative resilience value is provided. In our approach, we argue that there would be an intrinsic value for resilience, and thus, a county that is most resilient within a state could itself be non-resilient when compared to the ideal case. In addition, we are proposing the computation of CIRI using a GIS-based platform, which enables practitioners to efficiently analyze community resilience. This feature enables officials and decision makers to easily quantify the resilience level of their desired geographical area, abolishing the need for them to perform costly data collection and analysis. These features altogether deliver a new resilience metric that can be directly integrated within resilience-based applications and decision-making. The platform is ready to be used in the State of New Jersey, but it can be made available in other states. To the best of our knowledge, this online software depicts a first reported attempt that leverages the benefits of GIS features to quantify, in real time, the absolute resilience level of communities. Combining GIS and disaster resilience index is one the main contributions of this paper. Disasters are not bounded by specific political boundaries but are cross-regional. GIS-based quantification provides an efficient way to cover this fact by quickly calculating the resilience index of any area, even if it spans across multiple administrative regions.

The paper is structured as follows: In Sect. 2, we describe and examine approaches to represent community resilience and social vulnerability. In Sect. 3, we define different sectors that are critical for a community. In Sect. 4, we present our methodology to derive and quantify our community intrinsic resilience index. And in Sect. 5, we apply our metric within the State of New Jersey to assess its community resilience at the county level. In Sect. 6, we describe our GIS-based web platform. The conclusions are given in Sect. 7.

\section{Approaches for quantifying resilience}

There are many attempts to quantify both disaster resilience and social vulnerability through indices. The Center for Disease Control and Prevention (CDC) adopted a metric to quantify the vulnerability of a community to disaster, referred to as the CDC's Social Vulnerability Index (SVI) (Flanagan et al. 2011). SVI is based on four types of a community' features that describe the community's socio-economic status, household composition, minority status, housing and transportation (Fig. 1a). SVI relies on 15 variables obtained at the tract level and calculated on the census tract level that is the smallest geographic level that SVI handles. The variables are transformed to percentile rank of each census tract and are then summed to calculate the final SVI for each tract.

Cutter et al. (2003) introduced the Social Vulnerability to Environmental Hazards (SoVI) as an attempt to render the social vulnerability of a community as a metric using 
a

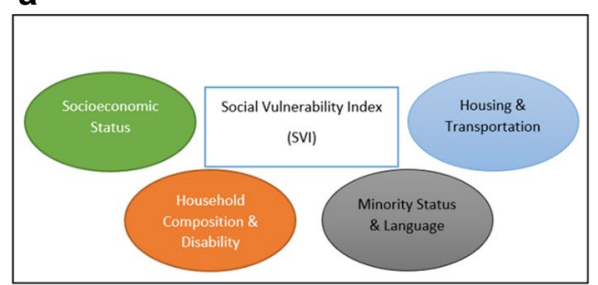

c

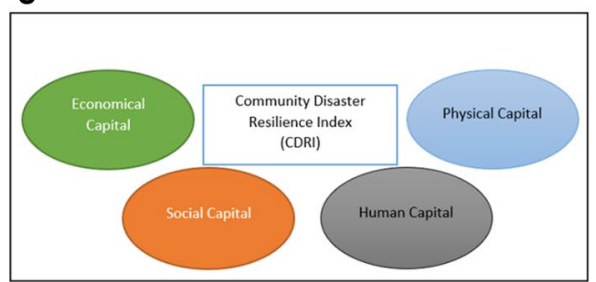

b

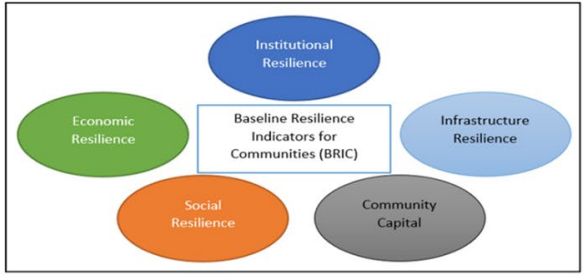

d

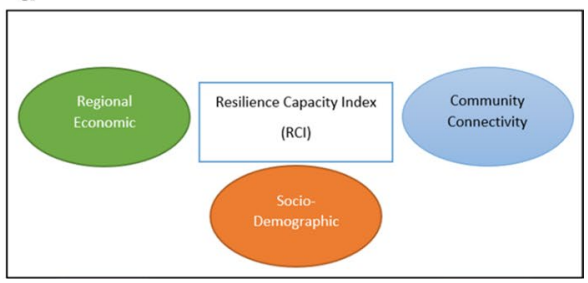

Fig. 1 Sub-components of a SVI, b BRIC, $\mathbf{c}$ CDRI and $\mathbf{d}$ RCI

socio-economic data. SoVI provides a tool to examine and detect characteristics that increase a community vulnerability to natural hazards. Although SVI and SoVI are vulnerability indices, they are often used within resilience research and application. Cutter et al. (2010) provided one of the first reported attempts to quantify community resilience regarding disasters for US counties, and they labeled it the Baseline Resilience Indicators for Communities (BRIC) (Fig. 1b). BRIC provides a baseline of conditions and characteristics from which one may examine the effectiveness of actions taken toward improving community resilience to disaster. Cutter et al. (2010) developed such index using data selected based on literature and availability and represent five different resilience subcomponents: social, economic, institutional, infrastructure and community capital (Fig. 1b).

Peacock et al. (2010) introduced the Community Disaster Resilience Index (CDRI), based on community attributes that represent four different capital domains: social, economic, physical and human (Fig. 1c). Each selected attribute influences one or more of the four disaster management phases: mitigation, preparedness, response and recovery. CDRI is computed by averaging the attributes within each capital domain to obtain four capital indices: CDR social-capital, CDR economic-capital, CDR physical-capital and CR human-capital. CDRI is the average of capital indices. Foster (2012) developed the Resilience Capacity Index (RCI), which measures the resilience capacity of metropolitan areas to natural disasters and economic shocks. It is the average value of different attributes representing three categories: regional economic, socio-demographic and community connectivity (Fig. 1d).

The essence of any approach trying to quantify resilience is the set of attributes used. The efficiency and validity of any index rely on choosing the right attributes that affect the resilience level of a community (Cutter et al. 2010). In other words, these chosen attributes should together describe how resilient a community is. Attributes are generally selected to represent certain categories that describe the community subdomains. Through studying the existing resilience quantification approach, diverse dynamic attributes were found to play a role in the vulnerability/resilience of a community. These attributes can be categorized into social, economic and infrastructure (Table 1). 
Table 1 General attributes used in constructing resilience and vulnerability indices

\begin{tabular}{ll}
\hline Sector & Attributes \\
\hline Social & $\begin{array}{c}\text { Poverty, Unemployment, Education, Age, Minority Status, Special Needs, } \\
\text { Language, Health Coverage, Religious Affiliation, Political Participation }\end{array}$ \\
Economic & $\begin{array}{c}\text { Poverty, Unemployment, Income, Single Sector Dependency, Housing Capital } \\
\text { Infrastructure }\end{array}$ \\
$\begin{array}{c}\text { House Structures, Transportation Access, Construction Establishments, Edu- } \\
\text { cation Establishments, Hospitals, Shelter Capacity }\end{array}$ \\
\hline
\end{tabular}

Correlating current resilience indices with the actual resilience of a community is an important step for validating such indices. Bakkensen et al. (2017) conducted an empirical study to compare and validate disaster indices. Using the effects (damages) as a result of a disaster, they tried to show their correlation with indices. These effects were represented by property damages, fatalities and number of disaster declarations. The results of the study show that only SoVI explained disaster declarations; CDRI, RCI and SVI were able to explain fatalities; and all of the studied indices explained property damages with the exception of BRIC. These results indicate that some are able to explain certain disaster outcomes better than others. As such, indices should specify their objectives and what disaster outcomes are taken into consideration.

Most of these indices are typically an aggregated summary of certain communities' attributes that are believed to affect resilience. One shortcoming of such a methodology is that attributes in most cases are normalized and averaged without taking into consideration the level to which each attribute affects the community resilience. In other words, each attribute is assumed to have an equal weight on resilience. For example, the BRIC index considers the number of public schools per square mile (recovery) to have the same effect on resilience as the number of hospital beds per 10,000 population (medical capacity). In addition, drawing conclusions on the resilience of a community based on such indices is achieved only based on comparisons. Thus, knowing how much a community is resilient is based on associating the resilience index of such place with another location. In addition, there would be always a "worst resilient" place, because of the ranking, while decision managers would need to simply know if a particular place is resilient. Finally, existing indices (e.g., Fig. 1) are based on the political boundary of an entity, and thus "dilute" the impact of a hurricane on a particular region. In reality, one might want to assess only a coastal plain area when dealing with coastal flooding rather then the whole county.

We argue for the adoption of a new resilience index, CIRI, that would fill the gaps in existing quantifiable metrics of resilience. CIRI provides the ability to assign different weights to various attributes instead of assuming that the impact of all attributes is equal. In addition, we deliver CIRI as an absolute index, rather than one based on ranking or comparison (existing indices). Furthermore, CIRI reflects the particular region of concern based on the physics (e.g., flooding in coastal areas) rather than based on the political boundaries. CIRI, built as a GIS-based web platform, offers practitioners with the flexibility to select and modify attributes, values, weights and locations. 


\section{Community resilience and community sectors}

To construct a resilience index of a community, our methodology consists of measuring/ quantifying the resilience level of four community sectors: transportation, energy, health and socio-economic. General categorization of community sector can refer to public and private sectors. In some contexts, community sectors refer to organizations and institutions that are operated by a local community instead of some federal agencies or state government (Edwards 2001). In this paper, community sectors refer to different formal and informal components, organizations, institutions and initiatives that operate by or within a community. In our methodology, we consider the sectors that are important to stay productive and be able to recover quickly following certain hazardous conditions. We note that there are other sectors that play an important role in resilience (e.g., ecological sector); however, we selected these crucial sectors based on data availability and usage in previous resilience and vulnerability indices. Furthermore, CIRI, as a quantification platform, is dynamic and will continuously be updated (attributes and sectors) based on the evolution of the science of resilience.

In the next subsections, we discuss these sectors, the attributes that affect their resilience level, and the perfect score of these attributes. A perfect score of an attribute represents its value in a best-case scenario.

\subsection{Transportation sector}

We regard the transportation sector as the set of systems and structures that are used for transportation and ensure the community mobility and connectivity. This sector embodies different components and sub-structures that make connectivity possible. These components range from roads, railroads, bridges, tunnels, cycling roads, etc., to bus stations and bus stops, ports, airports, etc. During a disaster, ensuring community mobility and connectivity is crucial in order to provide the citizens with the means and abilities to reach critical destinations such as hospitals and to evacuate the areas of danger. Mobility is important for officials and first responders to perform their duty during disasters. However, mobility is also important after the disaster to facilitate recovery.

In 2005, under the catastrophic impacts of hurricane Katrina that resulted in massive damages and fatalities (Brunkard et al. 2008), the city of New Orleans was heavily affected (Andersen et al. 2007; Coussens and Goldman 2007), with more than 100,000 persons confined to their homes, unable to evacuate. The inability to access the means for transportation (lack of private cars and dearth of public busses) in addition to poor planning from local governments was the main reason behind people being trapped inside their homes, with about 112,000 people lacked access to private cars at the time of the hurricane (Sullivan 2005, Litman 2006; Wolshon 2006; Sanchez and Brenman 2008).

Numerous studies have investigated the effects of a community transportation infrastructure on its economic growth. Sharif et al. (2019) examined the relationship between transportation and the economic growth in the USA using data from 2000 through 2017. Following the Quantile-on-Quantile approach introduced by Sim and Zhou (2015), they found a positive correlation between transportation and economic growth. Chen and Haynes (2015) showed the positive impact of public transportation infrastructure (highways, railroads, airports and public transit) on the regional economic growth of the US northeast megaregion. The existence of positive correlation between transportation (or 
general public infrastructure) and growth has been identified in different countries and areas as well (Wang 2002; Pereira and Andraz 2005; Boopen 2006; Hong et al. 2011; Sahoo and Dash 2012; Pradhan and Bagchi 2013). Public spending on transportation development is widely seen in US policies, proposals and in multiple presidential campaigns as a way for increasing economic growth (Tong et al. 2014). Economic growth and development highly shape communities and their level of preparedness and sustainability (Lerch 2017). Community resilience highly depends on a resilient local economy that relies on different sectors and provides diverse employment opportunities (Bentley and Pugalis 2013; Steiner and Atterton 2014).

The resilience of a transportation sector within the community can be defined as how well the sector can remain productive and how quickly it can recover following a disaster. Such resilience is influenced by multiple attributes:

- Road area: Road infrastructure is critical to both handle the flow of people evacuating an area and the flow of goods after the disaster. Traffic congestion can be seen as a demand/supply problem where the demand to roads surpasses what is available. Road capacity is the maximum number of vehicles per hour that can be served by such road (Ameri et al. 2013). Hence, increasing a road capacity will help coping with the traffic flow resulting in more vehicles being able to use such a road and vacate danger areas faster during disasters. The road capacity depends on the availability of roads within the community and the connectivity of the roads. Capturing these properties accurately is challenging, and for this reason we elect to use the road area (in square miles) to represent the capacity of road infrastructure. The situations where a long road is closed due to a bridge collapse within it could be accounted for by removing that road from the total available road areas. Nevertheless, the management of road connectivity and the optimization of traffic are beyond the purview of the current investigation, as our goal is to use simple means to assist in decision making.

While it is intuitive to report the total road area per the area of the region of interest, one would need to also consider the population of that region. For this purpose, we propose that one should use two metrics: road area per total area of the region and road area per population (e.g., per 1000 people). Within these metrics, non-paved roads are excluded from the quantification. We selected the "perfect scores" based on counties in New Jersey: Union County, NJ, has the highest road area to land area ratio among the other NJ counties, with $0.069 \mathrm{mi}^{2}$ of available road area per $1 \mathrm{mi}^{2}$ of land area, and thus, its value is considered the "perfect score." Salem County surpasses the other NJ counties in terms of road area to population ratio, at $0.07 \mathrm{mi}^{2}$ per 1000 population, and this value is considered the "perfect score." Note that the road area attribute presents a general top-level view of the road infrastructure within a community. During the resilience quantification process, practitioners might opt-in to only include roads based on certain requirements, such as evacuation routes, roads connecting to critical facilities, etc.

- Transit performance The ability of a community transit system (public transportation) to serve as many people as possible in efficient way is important to make mobility possible. In addition, a better public transportation will reduce the percentage of people using their own vehicle and thus results in a less traffic. Transit performance adopts the community AllTransit ${ }^{\mathrm{TM}}$ Performance Score (CNT 2019), which ranges from 0 to 10. This score is based on three different components of a region transit system: transit connectivity, job accessibility and frequency of transit services (Liu et al. 2020). As an 
example, a score of 10 was assigned to New York County, NY, while a score of 5 was assigned to Providence County, RI.

- Household vehicles: A high percentage of households having private vehicles means that mobility will be less affected by interruption in public transport services. During disasters, families with vehicles have a higher chance to evacuate effectively and quickly. An "ideal" situation, from a resilience perspective, would be that every household have at least one vehicle (note that this might not mean that such is ideal from a sustainability perspective). The average number of people per household is 2.52 in the USA (Census 2018). Hence, the perfect score is 400 vehicles per 1000 population. Evidently, an increase in the number of cars could cause congestions on normal days and potentially a lot of car emissions, but the focus herein is on community resilience to disasters, which is strengthened, in general, by redundancy.

\subsection{Energy sector}

Prior to the 1970s, economists did not consider energy as an explicit component in the production process and showed a little interest in exploring its impact (Alam 2008). This changed after the 1970s jump in oil price (Georgescu-Roegen 1975; Buenstorf 2004). However, it is now well established that there is a positive correlation between energy and industrial development (economic growth) (Alam 2008; Olufemi 2015). Thus, the energy sector is another important component of a community resilience. Energy infrastructure consists of different components that provide a community with the needed energy to power houses. Within the energy sector, we focused only on electricity given that quantifiable attributes that describe other components are not available. Practitioners, having such data, can easily include them in the quantification process. An unfailing, reliable and consistent energy source and operation is critical for the community economic and social functions (Amin 2001).

In this era, all the components of a community depend heavily on electricity. These components consist of entities that affect the well-being of the community, such as hospitals, transportation systems, communication systems, educational and financial institutions, etc. Usually critical entities, such as hospitals (NFPA 2009) and airports (FAA 2019), have back-up electric generators. But these generators are usually intended to cover the basic operation, and for a short duration. The electric power is, however, very important for households and small entities (typically not possessing backup generators), to have light in the houses, to operate the refrigerators and electric stoves and to charge phones (whether land line or cell phones). Electricity is commonly needed for heating or air conditioning, which could be crucial for older residents.

A resilient energy sector within the community is a sector that can deliver efficient and uninterrupted services during and following disasters. Power outages can be one of the effects of a disaster, and the degree of such outages indicates the level of resilience of the energy sector. Many characteristics play a role in having reliable power systems:

- Power distribution network: This attribute is the average of two subcomponents:

o Underground wires: Underground wiring renders electric power supply more reliable, as such infrastructure is immune to different weather conditions than overhead wires (Kaipia et al. 2007). 
o Quality of the network: Whether electric wires are underground or overhead, the quality of such wires is the key to a sustainable electric energy.

- Microgrids: The US Department of Energy defines microgrids as "a group of interconnected loads and distributed energy resources within clearly defined electrical boundaries that acts as a single controllable entity with respect to the grid" (Ton and Smith 2012). Kwasinski (2010) determined that microgrids enhance power supply resilience. In our implementation, this attribute is captured through the number of people using electric power transmitted via microgrids per 1000 population. A perfect score would be that all grids are microgrids (note that the quality of the power delivery network within a microgrid remains important).

- Renewable energy: Renewable energy can be obtained from solar panels (Mekhilef et al. 2011), domestic geothermal sources (Glassley 2014) or wind (Musgrove 2009). Renewable energy provides a clean and sustainable electric power, which according to the Committee on Climate Change (CCC 2010) and the United Nation Industrial Development Organization (UNIDO 2009) is a prerequisite for achieving an enhanced city resilience and a key for sustainable social, economic and industrial development (Jabareen 2013). Esteban and Portugal-Pereira (2014) evaluate the use of electricity system based on a 100\% renewable energy in Japan. They showed how such electricity system can increase electricity resilience. The authors used meteorological (wind and solar) data to forecast the future hourly renewable electricity production. They found that the predicted hourly electricity production matches the electricity demand in Japan. This finding indicates that using only renewable energy for electricity production can meet the electricity demand, while assuring a reliable supply. This attribute is captured using the number of people using electric power from a renewable source per 1000 population. A perfect score would be that all electric power within a community is generated from renewable source.

\subsection{Health sector}

The health sector or the health infrastructure of a community is represented by the set of health-related services and institutions that operate within the community. The CDC defines public health as the set of "all public, private and voluntary entities that contribute to the delivery of essential public health services within a jurisdiction" (CDC 2010). One of the main aims of public health infrastructure is to provide communities with the ability to prepare for and respond to threats to health (ODPHP 2020), by providing the public health system with the essential components to carry out public health functions (Institute of Medicine 2003). Having a resilient health sector is important to any community in order to provide reliable health services and treatments, especially following disasters (Bissell et al. 2004; Auf der Heide and Scanlon 2007; Frumkin et al. 2008).

Health resilience is the degree to which the health sector continues to provide reliable and efficient health services to residents following a disaster. Overcrowded hospitals and clinics, shortages in doctors and nurses, limited medications and disrupted emergency medical services are the kind of adverse effects of disasters on communities. The attributes that affect the health sector resilience are:

- Hospital beds: Following a disaster, hospitals might be subjected to an increased number of patients, which could overwhelm the hospital capacity (Yi et al. 2010). To miti- 
gate this challenge, a hospital should (simply) have enough number of beds. This attribute represents the number of hospital beds per 1000 population. In 2018, the average number of hospital beds per 1000 population in the USA is 2.4, with South Dakota having an average of 4.8, the highest among all the states (KFF 2018). Within the U.S, at the county level, the average number of beds per 1000 population is 3.0 (Healthcare 2020). We use the value of 4.8 per 1000 population as the perfect score. Beds in this scope include staffed and ICU beds in hospitals and medical centers.

- Practicing physicians: Having the needed number of health care institutions is inadequate without having enough doctors that could deliver the necessary care to patients. This attribute describes the number of practicing MDs (Doctor of Medicine) and DOs (Doctor of Osteopathic Medicine) per 1000 population. The USA has fewer physicians in comparison with other countries (Fig. 2), with an average of 2.6 practicing physicians per 1000 population (Kamal 2020), while it is around 4.0 in most of Europe. At the county level, the average ratio is around 1.5. We use 2.6 herein as the perfect score. It is also assumed that the number of physicians reflects the whole number of public health personnel (nurses, technicians for radiology, technicians for anesthesiology, etc.).

- Health insurance: Health cost is one of the hidden costs of natural disasters, given the severe health impacts of disasters on individuals (Heinz 2002). This attribute represents the number of insured individuals per 1000 population, as communities with high percentage of insured population exhibit higher level of resilience (Cutter et al. 2010; Peacock et al. 2010). Health insurance in this scope consists of private as well as public insurance (Medicaid, Medicare). A perfect score would reflect that everyone is insured. Although one might regard this perfect score as unattainable, such a score depicts the direction to which actions should be targeted. Moreover, other factors play a role within the health insurance component, such as the outreach, types of insurance, coverage, etc. However, we limited this attribute by the number of insured individuals, given that data describing other factors are unavailable. Moreover, the number of insured individuals provides a general top-level view of this attribute.

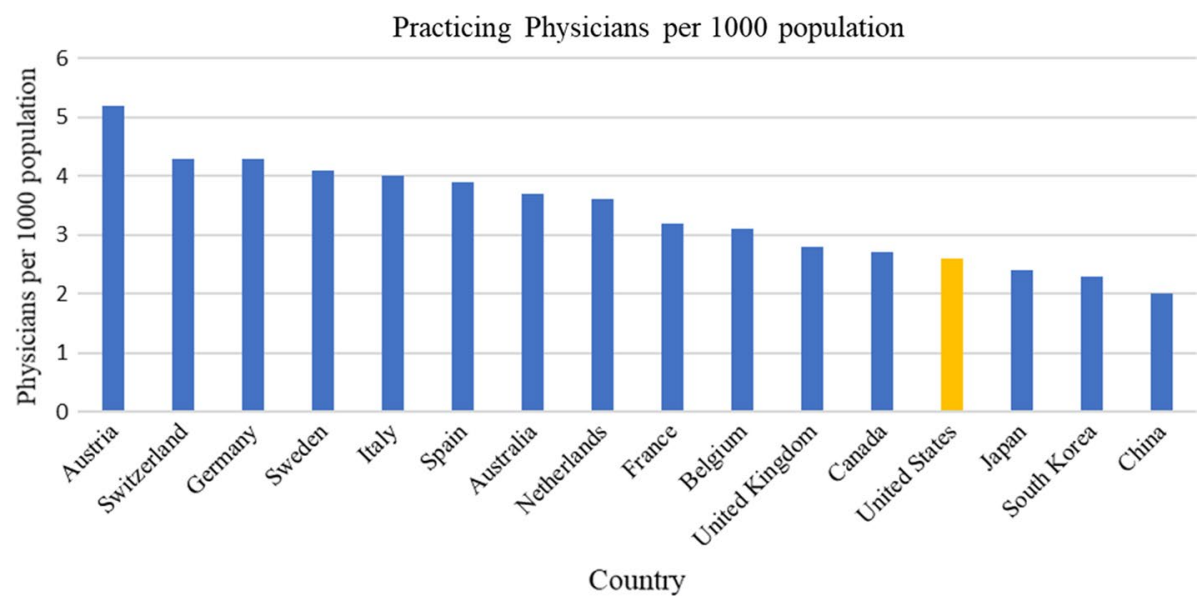

Fig. 2 Number of physicians per 1000 population for selected countries. Data from (Kamal 2020) 


\subsection{Socio-economic sector}

The socio-economic sector includes the services, institutions, operations and functions that are directly related to the day-to-day life of the people within a community. This follows from the work of Flanagan et al. (2011) which included the socio-economic status as a subcomponent in SVI. This sector encompasses the socioeconomic status which includes components such as education, income, occupation as well as quality of life attributes (APA 2020).

Socio-economic resilience can be regarded as the ability of people to prepare, adapt and quickly recover following a disaster. It describes the effects of a disaster on people's routine and how quickly they can restore their normal life, in terms of education, jobs and houses. Multiple attributes play a role in making the socio-economic sector more resilient:

- Education: Tierney (2006) argues that education has a positive influence on accessing and acting upon hazard information. Morrow (1999) shows as well how less educated people face difficulties in overcoming the pragmatic barriers to survive and recover from disasters. In our model, this attribute is represented by the number of people having at least a college degree per 1000 population (25 years and over). A perfect score (500) would be that half of the population have such degree or higher. We note herein that the education attribute might not apply for all types of communities, and practitioners in such places could exclude this attribute from the quantification, by giving it a weight equals to zero (0).

- Creative class: Creative class consists of the people employed in occupations that require novel combinations of knowledge and ideas, and the growth of such class positively influences the economic growth within a community (McGranahan and Wojan 2007). Sherrieb et al. (2010) list the following as creative occupations: construction, computer and mathematics, community and social service, life, physical and social sciences, management and farming, fishing and forestry. This attribute describes the number of people working in creative occupations per 1000 population (16 years and over). On the county level, the USA has an average of 142.11 people working in creative occupations (per 1000 population). We use 142 per 1000 population as a perfect score.

- StormReady: StormReady (NWS 2020a) is a program by the National Weather Service to provide communities with the needed communication and safety skills in order to decrease the effects of certain weather events on lives and properties. This attribute represents the number of people living in StormReady communities per 1000 population. A perfect score of 1000 depicts that everyone is living within such a community.

- Per capita income (PCI): According to Mayunga (2007), economic capital improves community and people's capacity to endure disasters as well as their ability to recover quickly. Per capita income (PCI) is an indicator of the community economic capital. PCI is the average income of a person within a specific area. The EPI's Family Budget Calculator is a tool created by the Economic Policy Institute in order to compute the income need of a person living within a specific area (Gould et al. 2015). A perfect score for the income (PCI) in a community would be equal to the cost of living computed by the Family Budget Calculator.

- Per capita GDP: According to Horn (1993), the economic wealth of an area is one of the main keys for the economic development. This can be described by the gross 
domestic product (GDP), which is the cumulative value (in dollars) of all the economic production within an area (Sherrieb et al. 2010). GDP is often used as an indicator to assess the economic impact of disasters (Pelling 2003). Herein, we use the annual GDP (in chained 2012 dollars) of a community reported per capita (ratio to population) as an attribute. In New Jersey in 2018, Somerset County had the highest GPD per capita among other NJ counties, according to the latest data gathered from the US Bureau of Economic Analysis (BEA 2018). As such, the perfect score of this attribute is its value for Somerset County (113,529 USD per 1000 population).

\section{Community intrinsic resilience index (CIRI)}

To measure the community resilience toward natural disasters, we aim to derive an absolute metric that can describe such resilience. We show this metric as a percentage describing the level to which such community is resilient. By doing so, this metric would be a standalone indicator for determining how resilient is a place (region) without the need for additional comparative analysis. A $100 \%$ resilience describes a perfectly resilient place that does not need enhancements.

An attribute with a value greater or equals to its perfect score is assigned the value $100 \%$. This could be justified by the fact that excess of a particular attribute might contribute little to increasing resilience. For example, if the power available to a community is more than what the community needs, the community would not detect the difference. Table 2 summarizes the attributes affecting the resilience of each sector, discussed in the previous section, along with their corresponding perfect score values. The selected values were shared informally with various stakeholders, and they appear to be plausible. One might need to change them based on local policies and initiatives. As such, our platform provides the flexibility for practitioners to change the perfect score as they see fit. One would need to perform local validation using a community's previous disaster experience in order to select the attributes that fit well the community.

\subsection{Quantification approach}

The resilience value of each sector is labeled using the letter $\mathrm{X}$ and is computed based on a linear combination of the corresponding attributes, viz.

$$
\begin{gathered}
X_{\text {Transportation }}=\sum_{i}^{\text {Transportation }} w_{\text {Transportation }}(i) * V_{\text {Transportation }}(i) \\
X_{\text {Energy }}=\sum_{i}^{\text {Energy }} w_{\text {Energy }}(i) * V_{\text {Energy }}(i) \\
X_{\text {Health }}=\sum_{i}^{\text {Health }} w_{\text {Health }}(i) * V_{\text {Health }}(i)
\end{gathered}
$$




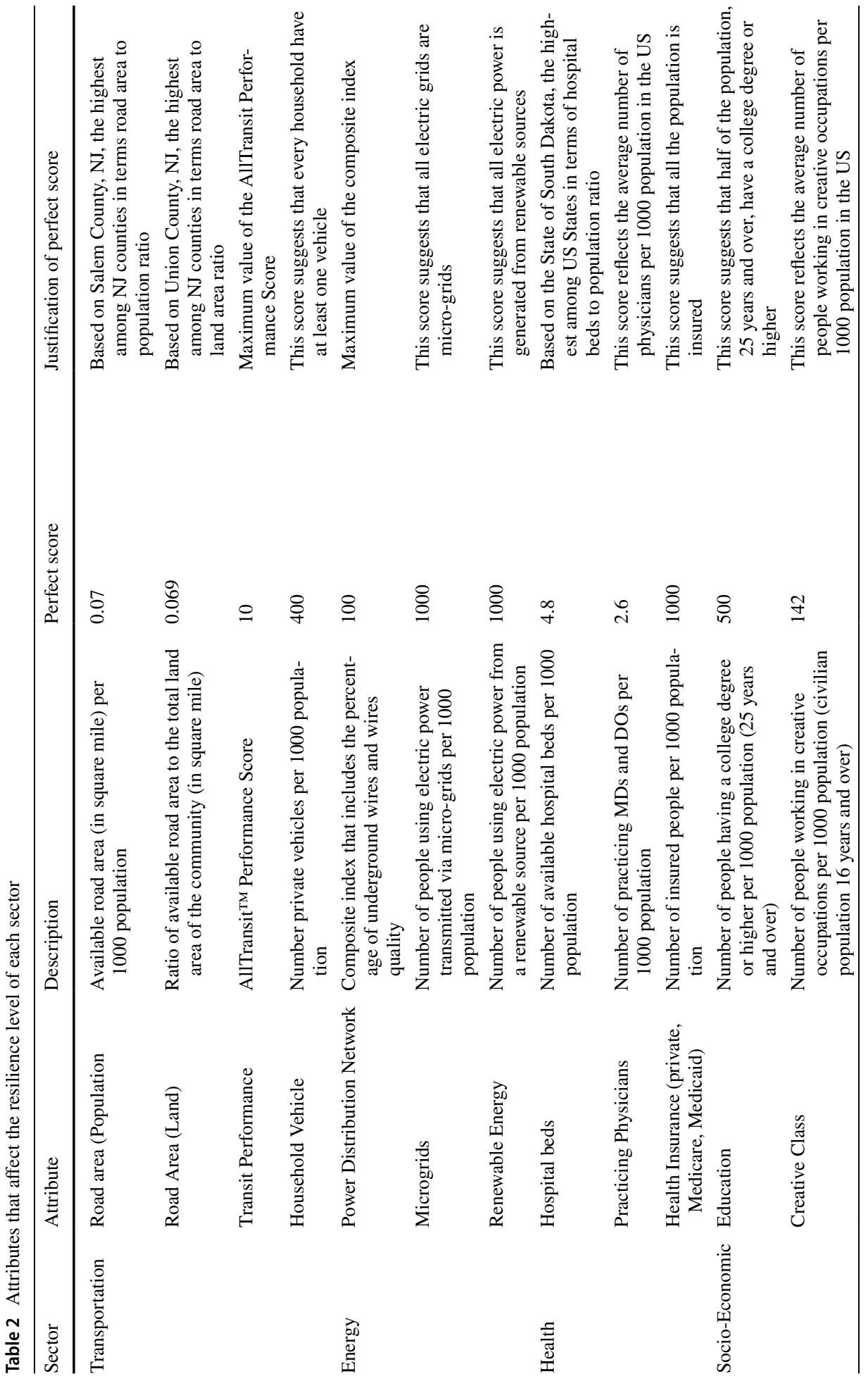




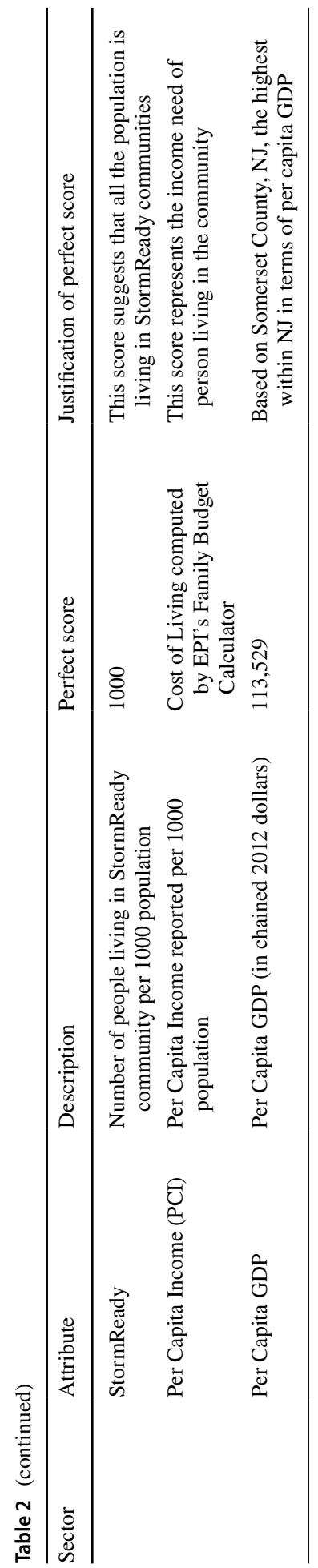




$$
X_{\text {Socio-Economic }}=\sum_{i}^{\text {Socio-Economic }} w_{\text {Socio-Economic }}(i) * V_{\text {Socio-Economic }}(i)
$$

where the "V" values represent the percentage of the actual values of the attributes in Table 2 normalized by their perfect scores in Table 2; thus, the numerical value of "V" ranges from 0 to $100 \%$. The terms $w_{\text {Transportation }}(\mathrm{i}), w_{\text {Energy }}(\mathrm{i}), w_{\text {Health }}(\mathrm{i})$ and $w_{\text {Socio-Economic }}$ (i) are the weights of each attribute within the corresponding sector. The sum of weights within each sector is 1 .

The Community Intrinsic Resilience Index (CIRI) is computed as a linear combination of the indices from four sectors: transportation, energy, health and socio-economic:

$$
\text { CIRI }=P *\left[\alpha_{T} X_{\text {Transportation }}+\alpha_{E} X_{\text {Energy }}+\alpha_{H} X_{\text {Health }}+\alpha_{S E} X_{\text {Socio-Economic }}\right]
$$

The weights " $\alpha$ " add up to 1.0, and they do not need to be equal. Note that although Eq. 2 assumes an independency between the factors and doesn't take into consideration the correlation between different factors, community sectors are interconnected, and the resilience of one, such as socio-economic, affects the resilience of the other sectors. However, practitioners are able to cover such inter-dependency when assigning weights, by focusing on attributes that effect different sectors. Within the scope of this research, sectors resilience metrics are not intended to be taken individually but together, within the overall CIRI index. If one needs to analyze a sector separately, such as the health sector, one will have to include, for example, certain socio-economic attributes.

The parameter $\mathrm{P}$ is the penalty term given as:

$$
\left\{\begin{array}{l}
P=1 \quad \text { if } V(i)>V_{\min }(i) \\
P=0.5 \quad \text { if } V(i)<V_{\min }(i) \text { and } V(j)>V_{\min }(j) \text { for } j \neq i \\
P=0.25 \text { if } V(i)<V_{\min }(i) \text { and } V(j)<V_{\min }(j) \text { for any } j \neq i
\end{array}\right.
$$

Table 3 Properties of attributes. Critical attributes are those that trigger the penalty term $\mathrm{P}$ (in Eq. 1) if they drop below a minimum (Eq. 3). Dynamic attributes are those change following a disaster and static attributes are time-invariant

\begin{tabular}{lll}
\hline Attribute & Critical & Type \\
\hline Road Area (Population) & Yes & Dynamic \\
Road Area (Land) & Yes & Dynamic \\
Transit Performance & No & Static \\
Household Vehicle & No & Static \\
Power Distribution Network & Yes & Dynamic \\
Microgrids & No & Dynamic \\
Renewable Energy & No & Dynamic \\
Hospital beds & Yes & Dynamic \\
Practicing Physicians & Yes & Dynamic \\
Health Insurance & No & Static \\
Education & No & Static \\
Creative Class & No & Static \\
StormReady & No & Static \\
Per Capita Income (PCI) & No & Static \\
Per Capita GDP & Yes & Dynamic \\
\hline
\end{tabular}


The term $P$ reflects the fact that if the value of a critical attribute (the critical attributes are indicated in Table 3 ) is too low and below a minimum value, $V_{\min }(i)$, it severely impacts the whole system. For example, if the number of hospital beds drops to $10 \%$ of what is acceptable, then resilience is severely reduced regardless of, for example, the presence of a sufficient number of physicians or a great transportation sector. This would be done herein by reducing the overall resilience index by $50 \%$. If two components are below the minimum values, the penalty parameter $P$ is set at 0.25 (which represents the multiplication by $0.5^{2}$ ), and thus, the resilience index is reduced by $75 \%$. Evidently, the " $P$ " and minimum values are arbitrary at this stage, and they are based on our judgment and experts' input; they can be changed as more information becomes available to calibrate the model. Within our GIS platform, practitioners would have the ability to change these values as they see fit. The penalty value approach is most applicable when evaluating post-disaster resilience as shown in Sect. 5.2.

\subsection{Weight calculation}

Assigning weights do not have to be the same across entities, as they could represent the relative importance of a particular sector to the political entity, such as a State. For example, the transportation sector might play a prominent role in a corridor State such as New Jersey, while the health sector might be very important for Florida, a state with a large number of elderly populations. Using our quantification approach, practitioners would be able to assign weights as they see fit, and one could follow the analytic hierarchy process (AHP) (Forman and Gass 2001) for an efficient assignment through prioritization, ranking and benchmarking against previous effects of disasters. For example, although education is included as one attribute within the socio-economic sector, certain communities rely more on the fact that their residents have better experience dealing with disasters than college graduates, living in urban cities. Practitioners in this case, using our framework, could easily handle such scenario by giving less weight to the "education" attribute and more to "StormReady" and "Creative Class."

The past performance of a community following a disaster could be also used to estimate the weights within a sector (Eq. 1) or for each sector (Eq. 2). However, such an approach might not be sufficient on its own due to the relatively small number of disasters in a particular region (maybe once a decade).

\subsection{Post-disaster CIRI}

Another limitation of existing approaches is that they assume that the resilience of a community is independent of the stress level (i.e., the magnitude of the disaster). Thus, the resilience level of a community is viewed as a static quantity. We argue that the resilience level should depend also on the disaster. Thus, a community could be $80 \%$ resilient following a 10 -year storm but then becomes $30 \%$ resilient following a 100 -year storm. For example, the number of available physicians in a community is an attribute that affects CIRI. During a disaster, such a number might decrease as some doctors might evacuate the area or they might not be able to reach their patients (Rodríguez and Aguirre 2006; Ochi et al. 2016). Thus, the recovery cannot depend only on the pre-disaster value of an attribute. Therefore, we introduce the post-disaster CIRI which can be used to calculate a new resilience level of a community following a disaster. The primary use of post-disaster CIRI is to run scenarios of future events, enabling practitioners to analyze the effects of 
a hypothetical disaster on resilience. However, one could also use post-disaster CIRI for real-time disasters analysis should the data be readily available. Currently, CIRI is not connected to real-time data input, a feature that we plan to tackle in the future.

Post-disaster CIRI can be calculated using the same attributes with updated input values. In order to achieve this, we describe two types of attributes: "static" and "dynamic." Static attributes are independent of the disaster, and their values remain the same (e.g., education level, number of insured people). Dynamic attributes have their values altered following a disaster (e.g., the acreage of roads available). Table 3 shows the type of each attribute used in CIRI.

\section{CIRI case study: coastal flooding in New Jersey}

Facing the current climatic changes and in attempt to build more resilient communities, Gov. Phil Murphy of New Jersey signed the Executive Order 89 (EO 89) on October 2019 ordering various government agencies to work together in order to cultivate policies and strategies that establish community resilience and develop a "Statewide Climate Change Resilience Strategy." New Jersey, consisting of 21 counties, is highly at risk with a possible 6.3 inches rise in sea level by 2100 (Kopp et al. 2019). On May 7th 2020, the New Jersey Department of Environmental Protection (NJDEP) hosted a webinar updating on the progress toward developing the Statewide Climate Change Resilience Strategy (NJDEP 2020). Key findings from the webinar detail the immediate threat of climate change on New Jersey, with $50 \%$ of the population living in coastal hazard areas.

\subsection{Pre-disaster resilience}

To assess the resilience capacity of New Jersey-based communities, we used our GIS framework to calculate CIRI of all the counties within New Jersey. We excluded the energy sector from our case study as we do not have these data (but State Governments would be able to obtain such data). Note that threshold values for all attributes were set to $0 \%$, which would prevent the penalty function (Eq. 3) from being triggered for the pre-disaster case study.

The CIRI values are shown in Fig. 3, and the percentage values of the attributes for each county are listed in Table 4. Note that we opt-in to assign equal weights for this case study.

NJ counties showed a transportation resilience level $\left(X_{\text {Transportation }}\right)$, ranging from $45 \%$ (Cumberland County) to $67 \%$ (Bergen County). In general, all counties showed a good vehicle to population ratio, ranging from 259 (Hudson County) to 394 (Cape May County) vehicles per 1000 population. Bergen county is the most resilient in terms of transportation. This is due to the fact that Bergen has a relatively high available road area to land area ratio, with $0.066 \mathrm{mi}^{2}$ per $1 \mathrm{mi}^{2}$ of land area. Cumberland County, on the other hand, is the least resilient in terms of transportation, with a road-to-land ratio of only 0.014 . Ocean also shows a poor transit performance, with an All Transit ${ }^{\mathrm{TM}}$ Performance score of 2.3. To enhance the resilience level of the transportation sector within Ocean County, officials need to focus on strengthening the transit performance. This could be achieved for example by increasing the connectivity of the public transportation system (more bus stops, new stations).

The health sector within NJ ranged from 55\% (Sussex County) to 97\% (Camden County). All counties showed a good score in terms of health insurance, varying from $87 \%$ 


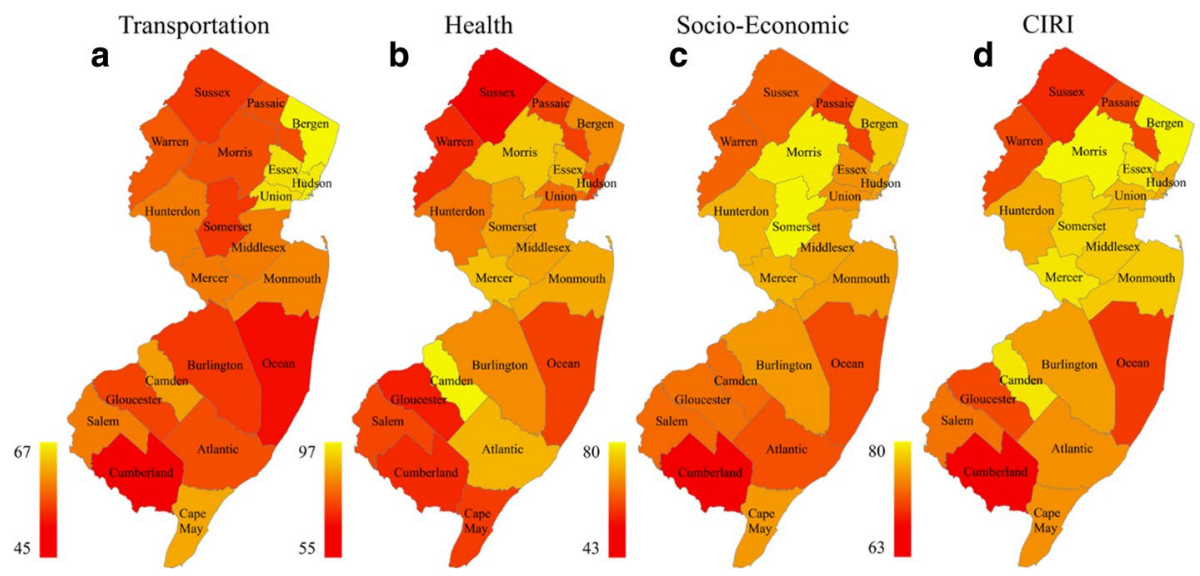

Fig. 3 Maps showing the resilience values of each section (Eq. 1) a $X_{\text {Transportation }} \mathbf{b} X_{\text {Health }} \mathbf{c} X_{\text {Socio-Economic }}$ and $\mathbf{d}$ CIRI for NJ counties. Colors change from red (least resilient) to yellow (most resilient). The transportation sector displays a resilience level ranging from 45 to $67 \%$, while the health sector resilience is relatively better ranging from 55 to $97 \%$. All counties show a socio-economic resilience varying between 43 and $80 \%$. Overall, CIRI ranges between 63 and 80\%, with Cumberland county being the least resilient

(Hudson County) to $96 \%$ (Hunterdon County) (percent of insured people). The relatively poor health resilience of Sussex County is due to the low number of hospital beds $(0.98$ bed per 1000 population) and practicing physicians (1.3 physicians per 1000 population). To enhance this sector, new policies should be established, aiming at increasing hospital capacities and available physicians.

For the socio-economic sector, the resilience level of NJ counties ranged from $43 \%$ (Cumberland County) to $80 \%$ (Somerset County). There are only few StormReady® communities in NJ, 7 counties out of 21. The highest is Cape May has a value of 25\% (250 people are living in StormReady® communities per 1000 population). It is followed by Bergen County (12\%) and Atlantic County (4\%). The annual per-capita income in Cumberland is 23,946 USD which accounts for only $63 \%$ of the cost of living in the county. Therefore, to enhance the socio-economic resilience, officials at Cumberland could focus on policies and incentives that would lead to the creation of new jobs and wage increases. Note that in a community such as Cumberland, education does not have that much effect on resilience and might be replaced, excluded or given less weight. Practitioners could achieve this by changing the weights within Cumberland County. In this case study, we opt-in to use unified sets of weights and attributes across communities for comparative reasons.

\subsection{Post-disaster resilience}

We demonstrate the effectiveness of CIRI in considering hypothetical scenarios of flooding in New Jersey. We will focus on coastal counties (Cumberland, Cape May, Atlantic, Ocean, Monmouth). We consider that coastal flooding caused the following: reduction in road area by $0.005 \mathrm{mi}^{2}$ per $\mathrm{mi}^{2}$ and reduction in per capita GDP by $\$ 18,000$. These reductions would be obtained based on scenarios of flooding and closure of the local economy. It is also assumed that the minimum values are $0.01 \mathrm{mi}^{2}$ per $\mathrm{mi}^{2}$ road area per area and $\$ 23,000$ for GDP per capita. This translates into $V_{\min }($ road area $/$ area $)=15 \%$ and $V_{\min }(G D P$ per capita $)=20 \%$. 
욜

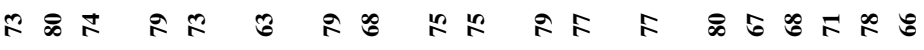

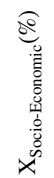

离芯苍

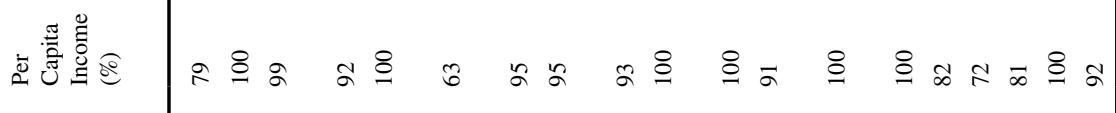
言逽 $+2+0$ a

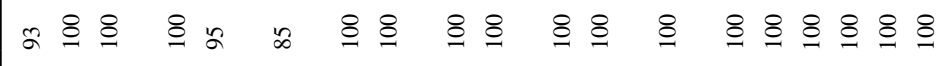

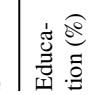

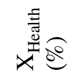

帚害 $\infty$

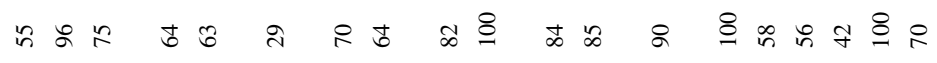

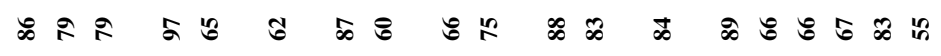
के ప สू के 这突

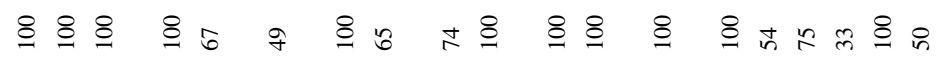




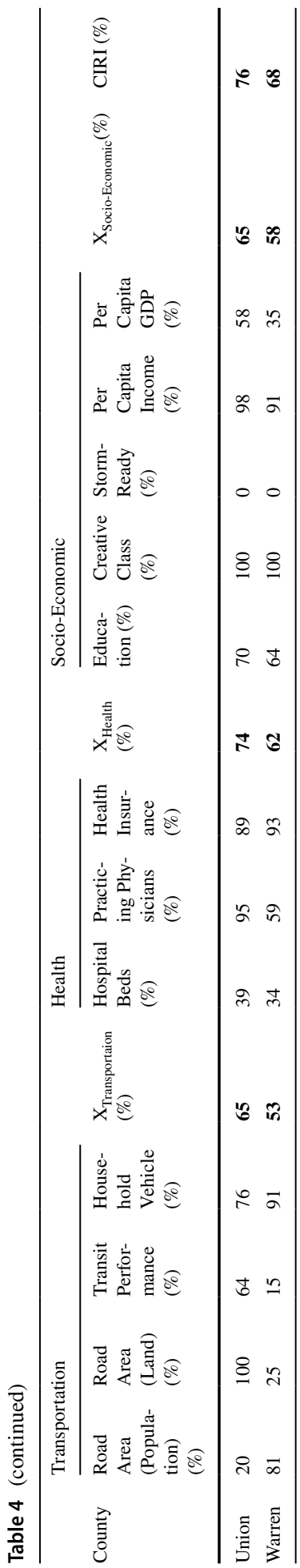




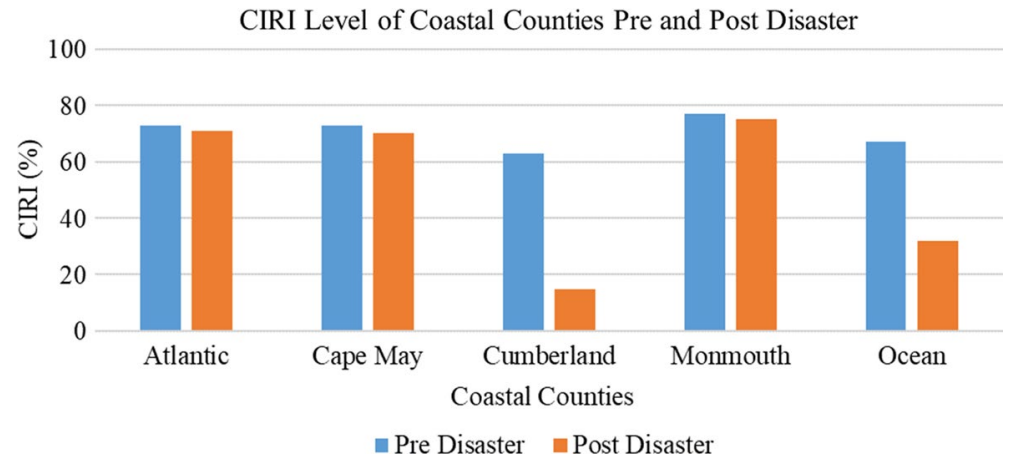

Fig. 4 Pre (blue)- and post (orange)-disaster CIRI level in coastal counties. Disaster was assumed to reduce available road area by $0.005 \mathrm{mi}^{2}$ per $\mathrm{mi}^{2}$ and the per capita GDP by $\$ 18,000$. In Cumberland, both the available road area and the GDP per capita dropped below the corresponding minimum values, which triggered the penalty function with $P=0.25$ (Eq. 3). In Ocean county, only the GDP dropped below the minimum value and triggered the penalty function with $P=0.5$ (Eq. 3)

The post-disaster resilience values for these counties are shown in Fig. 4, where one notes that Cumberland County is subjected to a tremendous decrease in its CIRI level from 63 to $15 \%$, which is due to the trigger of the penalty function. In other words, without external aid from the State or Federal, Cumberland County is not resilient (i.e., cannot recover).

\section{GIS-based web platform}

\subsection{Main interface}

The main web interface of the GIS platform is shown in Fig. 5 and can be accessed using (http://intrinsicresilienceindex.com/). The map depicts the ESRI world topographic layer, which provides a detailed basemap for the world. By default, the map shows the countries and states boundaries. We are using the ArcGIS API for JavaScript (version 4.16) to show the map and to use the GIS features provided by ESRI.

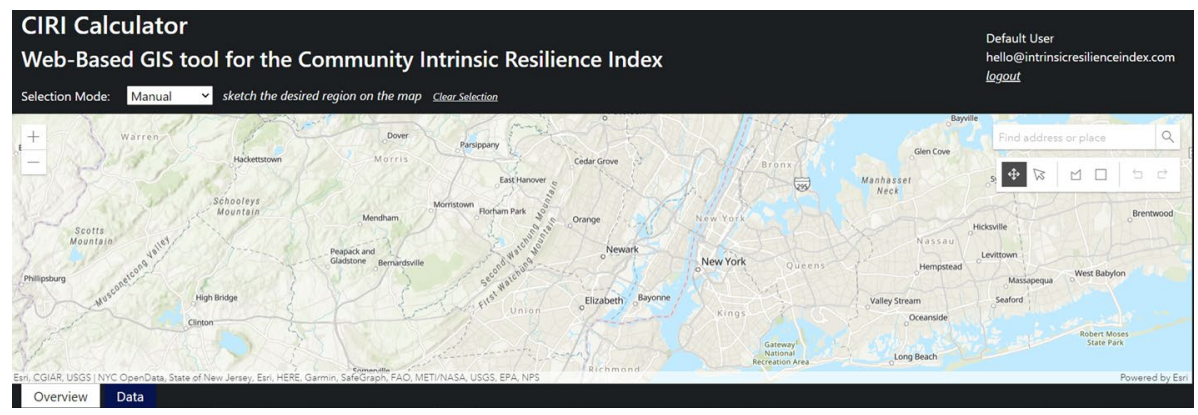

Fig. 5 Main interface of the Web-Based GIS tool for calculating CIRI 


\subsection{Area selection}

CIRI is not bounded by specific political boundaries and can be applied to any geographical area, granted that the required data are available. Within our platform, the census block groups are regarded as the smallest geographical entities, and data is stored at such level. As such, a selected location is viewed as a set of the block groups contained within. For ease of use, the software provides the users with the ability to select their desired location in three different way: County level, Municipality level and Manual selection. The latter offers the users with the capability to sketch the location on the map. Once a location is selected, the software extracts the corresponding block groups and performs the data computation explained in the next subsection.

\subsection{Data storage and computation}

For efficiency, data used in CIRI computation, except for road area, are extracted and saved in our own MySQL Database at the census block group level. The road area is extracted and calculated on real time using the road GIS layer published and maintained by the New Jersey office of GIS (NJOGIS). The road layer consists of a fully segmented road centerlines in New Jersey. Although one could only extract the length of the road from the feature layer, the road area can be estimated as such:

$$
\text { Road Area }=L * 2 * 0.00227273
$$

where Road Area is in sq mi; $L$ is the road length in mi. On average, a road consists of two lanes, hence the multiplication by 2 . The average width of a road lane is 12 feet $(0.00227273 \mathrm{mi})$.

Table 5 lists the sources used to extract the data, and Table 6 shows the GIS layers used within our platform.

Counties and municipalities layers are used to assist the user when selecting a desired location. Block groups layer is used to extract the census block groups within the selected area.

Table 5 Data sources

\begin{tabular}{ll}
\hline Data & Source \\
\hline Transit Performance & (CNT 2019) \\
Household Vehicle & (Census 2018) \\
Hospital beds & (Healthcare 2020) \\
Practicing Physicians & (HRSA 2017) \\
Health Insurance & (Census 2018) \\
Education & (Census 2018) \\
Creative Class & (Census 2018) \\
Storm Ready & (NWS 2020b) \\
Per Capita Income & (Census 2018) \\
Per Capita GDP & (BEA 2018) \\
\hline
\end{tabular}


Table 6 GIS Layers used in the CIRI web platform

\begin{tabular}{ll}
\hline Layer & Publisher \\
\hline NJ Road Centerlines & NJ Office of Information Technology, Office of GIS (NJOGIS) \\
NJ Counties Borders & NJ Office of Information Technology, Office of GIS (NJOGIS) \\
NJ Municipalities Borders & NJ Office of Information Technology, Office of GIS (NJOGIS) \\
USA Block Groups & ESRI
\end{tabular}

\subsection{Workflow}

Upon selecting a location, the software automatically computes the total road area (Eq. 4) in order to get the Road Area (Population) and Road Area (Land) attributes. The FIPS codes of the block groups contained within the selected place are also extracted, and the data needed for each block are extracted from the database. Figure 6 depicts the main architecture of our platform.

When processing is done, the CIRI level and each sector resilience are displayed. Users would be able to change the attribute weights, values, thresholds as well as sector weights and re-compute the resilience level. This also applies for the thresholds, sector weights and attribute values. The ability to change attribute values is crucial for officials and policy makers to study the effect of an action on the resilience.

\section{Conclusions}

Community resilience is viewed as the capacity of the community to prepare for, continue to function and recover following a disaster. Existing resilience indices (Fig. 1) are relative, depend on the political boundaries and do not account for the impact of the disaster itself on the resilience. We argued for the adoption of an absolute resilience index,

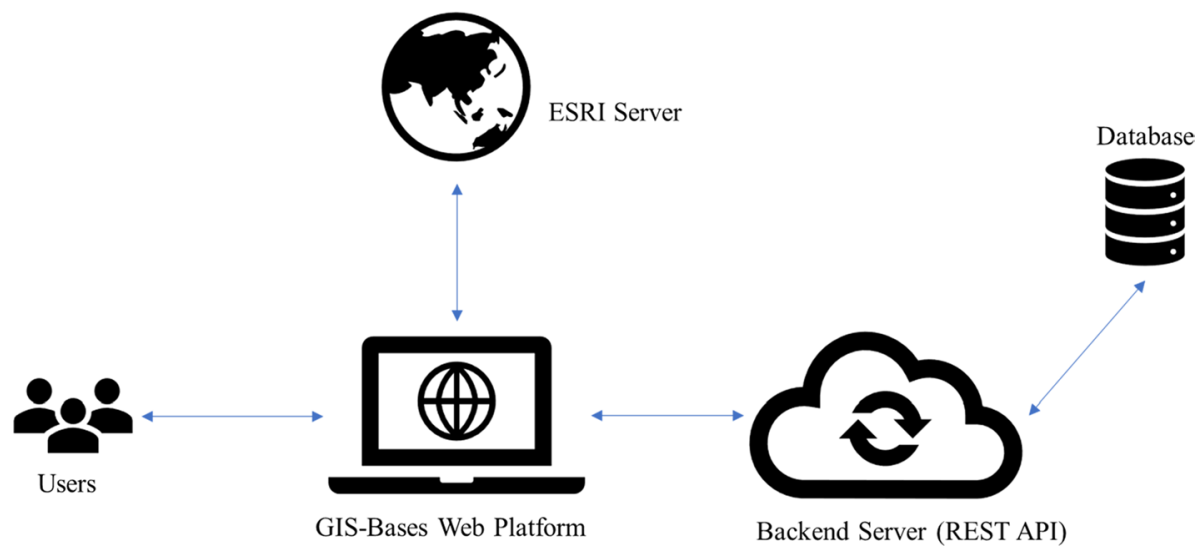

Fig. 6 Main architecture of the web platform. Users interact with the website which communicates with ESRI server to enable GIS features, and with a Rest API framework to perform the needed computations. The API communicates with an SQL database for data retrieval 
referred to as the Community Intrinsic Resilience Index (CIRI), and we considered it to be dependent on the resilience level of four community sectors: transportation, energy, health and socio-economic (Table 2). Within each sector, we selected attributes that affect the corresponding resilience level, and we introduced a perfect value (Table 2) for each such attribute, depicting its value in a best-case scenario. The use of a perfect value enabled us to transform attribute values into percentages, leading to an absolute resilience index, shown as a percentage that describes the level of resilience of a community. CIRI is computed as a linear combination of the resilience levels of the sectors (Eq. 2).

CIRI provides practitioners with the ability to assign different weights for attributes and sectors. We introduced in our quantification approach a penalty function that would significantly reduce the resilience of the community if one or more of the critical attributes fall below their lower threshold values (e.g., the roads are $90 \%$ shut). To simulate the effect of certain disasters on resilience, practitioners could use the Post-Disaster CIRI, which describes the new resilience level of a community following a disaster.

As a case study, we applied our approach on the counties within the state of New Jersey. CIRI of NJ counties ranged from 63\% (Cumberland County) to 80\% (Camden county) (Fig. 9d). Typically, counties that include cities have large health scores (number of beds, doctors, etc.) but low socio-economic scores.

We also used CIRI post-disaster, focusing on coastal counties (Cumberland, Cape May, Atlantic, Ocean, Monmouth), where we considered a hypothetical scenario of flooding in these counties. Post-disaster CIRI values for the coastal counties (Fig. 4) showed that CIRI of one county (Ocean) dropped to $30 \%$.

The main contribution of CIRI within the field of resilience application is that quantification is GIS based, considering that disasters are cross-regional, and assessing resilience should go beyond political boundaries. Moreover, having a GIS solution to compute resilience is crucial, as it would enable officials to efficiently examine and assess community preparedness to disasters, which would lead to a better disaster risk management. We believe that the use of GIS for resilience quantification makes a significant contribution toward filling the gap between the research and the practice part of community resilience.

Community leaders and strategists can use CIRI as a tool to identify and analyze the resilience level of their community. In addition, they can extract the weak sectors and areas that need to be enhanced in order to have a stronger and more resilient community, able to better endure a disaster. Community officials can use both CIRI and the post-disaster CIRI as a blueprint for the community recovery process.

We note a limitation of CIRI which corresponds to the community sectors used. There are other sectors that play an important role in resilience, and one should choose sectors that reflect the characteristics of the community of interest. CIRI, in terms of the index and the GIS tool, is scalable, and new sectors and attributes can easily be integrated. As more data become available, our future plan consists of continuously validating CIRI and adding new sectors and attributes.

Authors' contributions Firas Gerges wrote the paper, gathered the data, conducted the investigation and developed the GIS web platform. Hani Nassif analyzed the results and the GIS tool. Xiaolong Geng and Holly A. Michael analyzed the results and contributed to the writing. Michel C. Boufadel supervised the research, interpreted the data, contributed to the writing and to the development of the GIS web platform.

Funding Funding for this study was provided by the Bridge Resource Program (BRP) from the New Jersey Department of Transportation. 
The funders had no role in the design of the study and collection, analysis and interpretation of data and in writing or approving the manuscript.

Data availability Data sources are listed in Tables 5 and 6. We made available a dataset for NJ census block groups: https://figshare.com/s/c13e62954b7efa4dfaff

Code availability Software Name: Web-Based GIS tool for the Intrinsic Resilience Index, Year First Available: 2020, Hardware Requirements: None, Software Requirements: Web Browser (Chrome, IE, Safari, etc.), Internet Connection, Availability: http://intrinsicresilienceindex.com, Cost: Free of Charge, Program Languages/Frameworks:Frontend: HTML, JavaScript, CSS; Backend: Laravel Framework (PHP), SQL

\section{Declarations}

Conflict of interest The authors have no conflicts of interest to declare that are relevant to the content of this article.

Human and animal rights This research does not involve human or animal participants.

Open Access This article is licensed under a Creative Commons Attribution 4.0 International License, which permits use, sharing, adaptation, distribution and reproduction in any medium or format, as long as you give appropriate credit to the original author(s) and the source, provide a link to the Creative Commons licence, and indicate if changes were made. The images or other third party material in this article are included in the article's Creative Commons licence, unless indicated otherwise in a credit line to the material. If material is not included in the article's Creative Commons licence and your intended use is not permitted by statutory regulation or exceeds the permitted use, you will need to obtain permission directly from the copyright holder. To view a copy of this licence, visit http://creativecommons.org/licenses/by/4.0/.

\section{References}

BEA. (2018). "GDP by County, Metro, and Other Areas." Retrieved August 21, 2020, from https://www. bea.gov/data/gdp/gdp-county-metro-and-other-areas.

Alam MS (2008) Bringing Energy Back Into the Economy: Examining Economic Growth With Energy. SSRN J. https://doi.org/10.2139/ssrn.950211

Ameri M, Moayedfar R, Jafari F (2013) Determination the capacity of two-lane suburban roads with neural networks and effect of speed on level of service. Eur Transp Res Rev 5(4):179-184

Amin M (2001) Toward self-healing energy infrastructure systems. IEEE Comput Appl Power 14(1):20-28

Andersen, C. F., J. A. Battjes, D. E. Daniel, B. Edge, W. Espey, R. B. Gilbert, T. L. Jackson, D. Kennedy, D. S. Mileti and J. K. Mitchell (2007). "The New Orleans hurricane protection system: what went wrong and why." A Report by the American Society of Civil Engineers Hurricane Katrina External Review Panel (Reston).

APA. (2020). "Education and socioeconomic status." American Psychological Association Retrieved June 2 2020, from https://www.apa.org/pi/ses/resources/publications/education.

Auf der Heide, E. and J. Scanlon (2007). "The role of the health sector in planning and response." Emergency management: Principles and practice for local government: 183-206.

Bakkensen LA, Fox-Lent C, Read LK, Linkov I (2017) Validating resilience and vulnerability indices in the context of natural disasters. Risk Anal 37(5):982-1004

Bentley G, Pugalis L (2013) New directions in economic development: Localist policy discourses and the Localism Act. Local Econ 28(3):257-274

Bergstrand K, Mayer B, Brumback B, Zhang Y (2015) Assessing the relationship between social vulnerability and community resilience to hazards. Soc Indic Res 122(2):391-409

Berke P, Newman G, Lee J, Combs T, Kolosna C, Salvesen D (2015) Evaluation of networks of plans and vulnerability to hazards and climate change: A resilience scorecard. J Am Plann Assoc 81(4):287-302

Bissell RA, Pinet L, Nelson M, Levy M (2004) Evidence of the effectiveness of health sector preparedness in disaster response: the example of four earthquakes. Fam Community Health 27(3):193-203 
Blaikie P, Cannon T, Davis I, Wisner B (2005) At risk: natural hazards, people's vulnerability and disasters. Routledge

Boopen S (2006) Transport infrastructure and economic growth: evidence from Africa using dynamic panel estimates. Empirical Econ Lett 5(1):37-52

Bosher, L. and K. Chmutina (2017). Disaster risk reduction for the built environment, Wiley Online Library.

Brunkard J, Namulanda G, Ratard R (2008) Hurricane katrina deaths, louisiana, 2005. Disaster Med Public Health Prep 2(4):215-223

Buenstorf, G. (2004). The economics of energy and the production process: an evolutionary approach, Edward Elgar Publishing.

CCC, C. o. C. C. (2010). "Building a low carbon economy-the UK's innovation challenge." http://www. theccc.org.uk/.

CDC, C. f. D. C. a. P. (2010) National Public Health Performance Standards Program (NPHPSP), CDC: Atlanta. GA, USA

Census. (2018). "United States Census Bureau." Census.gov.

Chen Z, Haynes KE (2015) Regional impact of public transportation infrastructure: A spatial panel assessment of the US Northeast megaregion. Econ Dev Q 29(3):275-291

CNT. (2019). "AllTransitTM Rankings." The Center for Neighborhood Technology Retrieved April 9 , 2020, from https://alltransit.cnt.org/rankings/.

Cochrane HC (1975) Natural hazards and their distributive effects. University of Colorado Boulder, Institute of Behavioral Science

Coussens C and Goldman L (2007). Environmental Public Health Impacts of Disasters: Hurricane Katrina: Workshop Summary, National Academies Press.

Cutter SL (2016) The landscape of disaster resilience indicators in the USA. Nat Hazards 80(2):741-758

Cutter SL, Boruff BJ, Shirley WL (2003) Social vulnerability to environmental hazards. Soc Sci Q 84(2):242-261

Cutter SL, Barnes L, Berry M, Burton C, Evans E, Tate E, Webb J (2008) A place-based model for understanding community resilience to natural disasters. Glob Environ Chang 18(4):598-606

Cutter SL, Burton CG, Emrich CT (2010) Disaster resilience indicators for benchmarking baseline conditions. J Homeland Security Emergency Manag. https://doi.org/10.2202/1547-7355.1732

Edwards M (2001) Participatory governance into the future: roles of the government and community sectors. Aust J Public Adm 60(3):78-88

Esteban M, Portugal-Pereira J (2014) Post-disaster resilience of a $100 \%$ renewable energy system in Japan. Energy 68:756-764

FAA (2019). "ORDER JO 6030.20G: Electrical Power Policy." Federal Aviation Administration, Air Traffic Organization Policy

Sullivan, L. (2005). "How New Orleans' evacuation plan fell apart." National Public Radio.

Musgrove, P. (2009). "Wind power." Cambridge Books.

Gouglidis, A. and D. Hutchison (2017). "Protection against Cyber Attacks: Introducing Resilience for SCADA Networks." Symposium on Innovative Smart Grid Cybersecurity Solutions.

Flanagan, B. E., E. W. Gregory, E. J. Hallisey, J. L. Heitgerd and B. Lewis (2011). "A social vulnerability index for disaster management." Journal of homeland security and emergency management 8(1).

Forman EH, Gass SI (2001) The analytic hierarchy process-an exposition. Oper Res 49(4):469-486

Foster KA (2012) In search of regional resilience. Urban Regional Policy Effects: Build Resilient Regions 4:24-59

Frumkin H, Hess J, Luber G, Malilay J, McGeehin M (2008) Climate change: the public health response. Am J Public Health 98(3):435-445

Georgescu-Roegen, N. (1975). "Energy and economic myths." Southern economic journal: 347-381.

Glassley WE (2014) Geothermal energy: renewable energy and the environment. CRC Press

Gould E, Cooke T, Kimball W (2015) What families need to get by. Economic Policy Institute 403:1-10

Healthcare, D. (2020). Definitive Healthcare: USA Hospital Beds. https://www.definitivehc.com/.

Heinz, C. (2002). "Human links to coastal disasters." The H. John Heinz III Center for.

Hong J, Chu Z, Wang Q (2011) Transport infrastructure and regional economic growth: evidence from China. Transportation 38(5):737-752

Horn RV (1993) Statistical Indicators: For the Economic and Social Sciences. Cambridge University Press

HRSA (2017). Area Health Resources Files. Health Workforce H. R. S. Administration.

Institute of Medicine, C. o. A. t. h. o. t. p. i. t. s. C. (2003) The Future of the Public's Health in the 21 st Century. DC, The National Academies Press, Washington

Jabareen Y (2013) Planning the resilient city: Concepts and strategies for coping with climate change and environmental risk. Cities 31:220-229 
Juntunen, L. (2004). Addressing social vulnerability to hazards, University of Oregon.

Kaipia, T., J. Lassila, J. Partanen and J. Lohjala (2007). A cost analysis method for storm caused extensive outages in distribution networks. CIRED 19th international conference on electricity distribution, Vienna, Austria.

Kamal, R. K., Nisha; McDermott, Daniel; Cox, Cynthia. (2020). "How prepared is the US to respond to COVID-19 relative to other countries?" Peterson-KFF Health System Tracker Retrieved June 2 2020, 2020, from https://www.healthsystemtracker.org/chart-collection/how-prepared-is-the-us-torespond-to-covid-19-relative-to-other-countries/\#item-start.

Karl TR, Trenberth KE (2003) Modern global climate change. Science 302(5651):1719-1723

Karl TR, Melillo JM, Peterson TC, Hassol SJ (2009) Global climate change impacts in the United States. Cambridge University Press

KFF. (2018). "Hospital Beds per 1,000 Population by Ownership Type." Kaiser Family Foundation Retrieved June 2 2020, from https://www.kff.org/other/state-indicator/beds-by-ownership.

Khazai B, Anhorn J, Burton CG (2018) Resilience Performance Scorecard: Measuring urban disaster resilience at multiple levels of geography with case study application to Lalitpur, Nepal. Int J Disaster Risk Reduct 31:604-616

Kilgore, R., W. O. Thomas Jr, S. Douglass, B. Webb, K. Hayhoe, A. Stoner, J. M. Jacobs, D. B. Thompson, G. R. Herrmann and E. Douglas (2019). Applying Climate Change Information to Hydrologic and Coastal Design of Transportation Infrastructure: Design Practices.

Koliou M, van de Lindt JW, McAllister TP, Ellingwood BR, Dillard M, Cutler H (2020) State of the research in community resilience: Progress and challenges. Sustain Resilient Infrastruct 5(3):131-151

Kopp, R. E., C. J. Andrews, A. Broccoli, A. Garner, D. Kreeger, R. Leichenko, N. Lin, C. M. Little, J. A. Miller and J. K. Miller (2019). "New Jersey's Rising Seas and Changing Coastal Storms: Report of the 2019 Science and Technical Advisory Panel."

Kwasinski A (2010) Technology planning for electric power supply in critical events considering a bulk grid, backup power plants, and micro-grids. IEEE Syst J 4(2):167-178

Lavelle, F. M., L. A. Ritchie, A. Kwasinski and B. Wolshon (2015). "Critical assessment of existing methodologies for measuring or representing community resilience of social and physical systems." NIST GCR: $15-1010$.

Lerch D (2017) The community resilience reader: Essential resources for an era of upheaval. Island Press

Litman T (2006) Lessons from Katrina and Rita: What major disasters can teach transportation planners. J Transp Eng 132(1):11-18

Liu J, Nambisan S, Li X, Fu X (2020) Are young Americans carless across the United States? A spatial analysis. Trans Res Part D: Trans Environ 78:102197

Mayunga JS (2007) Understanding and applying the concept of community disaster resilience: a capitalbased approach. Summer Academy Social Vulnerability Resilience Build 1(1):1-16

McGranahan D, Wojan T (2007) Recasting the creative class to examine growth processes in rural and urban counties. Reg Stud 41(2):197-216

Mekhilef S, Saidur R, Safari A (2011) A review on solar energy use in industries. Renew Sustain Energy Rev 15(4):1777-1790

Mileti D (1999) Disasters by design: A reassessment of natural hazards in the United States. Joseph Henry Press

Morrow BH (1999) Identifying and mapping community vulnerability. Disasters 23(1):1-18

NFPA, N. F. P. A. (2009). "NFPA 101." Life safety code, National Fire Protection Association, Massachusetts, USA.

NJDEP (2020). Climate Change Resilience Strategy Virtual Information Session.

Norris FH, Stevens SP, Pfefferbaum B, Wyche KF, Pfefferbaum RL (2008) Community resilience as a metaphor, theory, set of capacities, and strategy for disaster readiness. Am J Community Psychol 41(1-2):127-150

NRC (2013). An Ecosystem Services Approach to Assessing the Impacts of the Deepwater Horizon Oil Spill in the Gulf of Mexico, The National Academies Press.

NWS (2020a) "NWS StormReady® Program." Retrieved May 23, 2020, from https://www.weather.gov/ stormready/communities.

NWS (2020b) "StormReady in New Jersey." Retrieved April 9, 2020, from https://www.weather.gov/storm ready/nj-sr.

Ochi S, Tsubokura M, Kato S, Iwamoto S, Ogata S, Morita T, Hori A, Oikawa T, Kikuchi A, Watanabe Z (2016) Hospital staff shortage after the 2011 triple disaster in Fukushima, Japan-an earthquake, tsunamis, and nuclear power plant accident: a case of the Soso District. PloS one 11(10):e0164952 
ODPHP, O. o. D. P. a. H. P. (2020). "Public Health Infrastructure." Healthy People 2020 Retrieved August, 17, 2020, from https://www.healthypeople.gov/2020/topics-objectives/topic/public-health-infrastruc ture.

Olufemi OJ (2015) "The effects of electricity consumption on industrial growth in Nigeria." Energy 6(13).

Parry M, Parry ML, Canziani O, Palutikof J, Van der Linden P, Hanson C (2007) Climate change 2007-impacts, adaptation and vulnerability: Working group II contribution to the fourth assessment report of the IPCC. Cambridge University Press

Patel SS, Rogers MB, Amlôt R and Rubin GJ (2017). "What do we mean by'community resilience'? A systematic literature review of how it is defined in the literature." PLoS currents 9.

Peacock WG, Brody SD, Seitz WA, Merrell WJ, Vedlitz A, Zahran S, Harriss RC, Stickney R (2010). "Advancing Resilience of Coastal Localities: Developing, Implementing, and Sustaining the Use of Coastal Resilience Indicators: A Final Report. Hazard Reduction and Recovery Center." Hazard reduction and recovery center.

Pelling M (2003). The vulnerability of cities: natural disasters and social resilience, Earthscan.

Pereira AM, Andraz JM (2005) Public investment in transportation infrastructure and economic performance in Portugal. Rev Dev Econ 9(2):177-196

Pfefferbaum BJ, Reissman DB, Pfefferbaum RL, Klomp RW, Gurwitch RH (2008) Building resilience to mass trauma events. Springer, Handbook of injury and violence prevention, pp 347-358

Pradhan RP, Bagchi TP (2013) Effect of transportation infrastructure on economic growth in India: the VECM approach. Res Transp Econ 38(1):139-148

Rodríguez H, Aguirre BE (2006) Hurricane Katrina and the healthcare infrastructure: a focus on disaster preparedness, response, and resiliency. Front Health Serv Manage 23(1):13

Sahoo P, Dash RK (2012) Economic growth in South Asia: Role of infrastructure. J Int Trade Econ Dev 21(2):217-252

Sanchez TW, Brenman M (2008) Transportation equity and environmental justice: Lessons from hurricane Katrina. Environ Justice 1(2):73-80

Serfilippi E, Ramnath G (2018) Resilience measurement and conceptual frameworks: a review of the literature. Ann Public Cooperative Econ 89(4):645-664

Sharif A, Shahbaz M, Hille E (2019) The transportation-growth nexus in USA: Fresh insights from pre-post global crisis period. Trans Res Part Policy Practice 121:108-121

Sherrieb K, Norris FH, Galea S (2010) Measuring capacities for community resilience. Soc Indic Res 99(2):227-247

Sim N, Zhou H (2015) Oil prices, US stock return, and the dependence between their quantiles. J Bank Finance 55:1-8

Steiner A, Atterton J (2014) The contribution of rural businesses to community resilience. Local Econ 29(3):228-244

Stocker T, Qin D, Plattner G, Tignor M, Allen S, Boschung J, Nauels A, Xia Y, Bex V, Midgley P (2013) IPCC, 2013: summary for policymakers in climate change 2013: the physical science basis, contribution of working group I to the fifth assessment report of the intergovernmental panel on climate change. Camb. Univ. Press Camb, UKNY NY USA

Tierney K (2006) Social inequality: Humans and disasters. Lessons From Hurricane Katrina, Philadelphia, University of Pennsylvania Press, On risk and disaster

Ton DT, Smith MA (2012) The US department of energy's microgrid initiative. Electr J 25(8):84-94

Tong T, Yu E, Roberts RK (2014) Dynamics of transport infrastructure, exports and economic growth in the United States. J Transp Res Forum. https://doi.org/10.5399/osu/jtrf.53.1.4204

UNIDO, U. N. I. D. O. (2009). "Energy and climate change: Greening the industrial agenda." http://www. unido.org/.

USGCRP (2017). "Climate Science Special Report: Fourth National Climate Assessment, Volume I." U.S. Global Change Research Program.

Wang EC (2002) Public infrastructure and economic growth: a new approach applied to East Asian economies. J Policy Modeling 24(5):411-435

Wolshon B (2006) Evacuation planning and engineering for Hurricane Katrina. Bridge 36(1):27-34

Yi P, George SK, Paul JA, Lin L (2010) Hospital capacity planning for disaster emergency management. Socioecon Plan Sci 44(3):151-160

Yoon DK, Kang JE, Brody SD (2016) A measurement of community disaster resilience in Korea. J Environ Planning Manag 59(3):436-460

Publisher's Note Springer Nature remains neutral with regard to jurisdictional claims in published maps and institutional affiliations. 


\section{Authors and Affiliations}

\section{Firas Gerges $^{1,2} \cdot$ Hani Nassif $^{3} \cdot$ Xiaolong Geng $^{1} \cdot$ Holly A. Michael $^{4}$.} Michel C. Boufadel ${ }^{1}$ (D)

Firas Gerges

firas.gerges@gmail.com

Hani Nassif

nassif.hani@gmail.com

Xiaolong Geng

gengxiaolong@gmail.com

Holly A. Michael

hmichael@udel.edu

1 Center for Natural Resources, Department of Civil and Environmental Engineering, New Jersey Institute of Technology, University Heights, Newark, NJ 07102, USA

2 Department of Computer Science, New Jersey Institute of Technology, University Heights, Newark, NJ 07102, USA

3 Department of Civil and Environmental Engineering, Rutgers University-New Brunswick, Piscataway, NJ 08854, USA

4 Department of Civil and Environmental Engineering, The University of Delaware, Wilmington, DE 19802, USA 